\title{
Evaluation of Scientific Research Based on Key Performance Indicators (KPIs): A Case Study in Al-Imam Mohammad Ibn Saud Islamic University
}

\author{
Fahad Omar Alomary ${ }^{1}$ \\ ${ }^{1}$ College of Computer and Information Sciences, Al-Imam Mohammad Ibn Saud Islamic University, Riyadh, \\ Saudi Arabia \\ Correspondence: College of Computer and Information Sciences, Al-Imam Mohammad Ibn Saud Islamic \\ University, Riyadh, Saudi Arabia.
}

Received: October 14, 2019

Accepted: December 30, 2019

Online Published: January 10, 2020

doi:10.5539/cis.v13n1p34

URL: https://doi.org/10.5539/cis.v13n1p34

\begin{abstract}
Several years ago Key Performance Indicators (KPIs) becoming a best measurement practiced by the government sectors. The Ministry of Higher Education in Saudi Arabia opens up to new technology, opportunities, and improved ways to acquire and disseminate scientific teaching and research to bring quality at par with the international standards. KPIs provide quality assurance to the scientific research and higher education. The KPIs are variable and designed specifically for a particular entity such as education, research, finance, operation management etc. Scientific research in Saudi Arabia needs special attention from governing bodies and those who are already involved in scientific research. In case of Al-Imam Muhammad Ibn Saud Islamic University (IMAMU), performance indicators are implemented but with skepticism. In future research, the Ministry of Higher Education, Saudi Arabia should provide the best indicators to measure the performance of Saudi universities by putting some value added in implementation of KPIs. Furthermore, third parties such as government servant and stakeholders should togetherness in performing their jobs to make sure everybody is complying with KPIs sets by its agencies.
\end{abstract}

Keywords: Al-Imam Muhammad Ibn Saud Islamic University, performance indicators, key performance indicators, scientific research, Saudi Arabia

\section{Introduction}

\subsection{Introduce the Problem}

Research in philosophy is that "Research is to see what each physique else has seen, however to assume what no person else has thinking (Annett 2009)" The aims and scope of scientific research harmonize the essence in the feel that thinking through the scientists is critical than seeing the results. The scientific research is of paramount importance, significantly influencing industrial, scientific and operational trends globally. During the last three decades, investment on scientific research was exponential, which has modified many traditional universities to "Research Universities". As the have an effect on grew on the world financial system and geopolitics, scientific lookup has established its priorities round the world.

The outcome of scientific research performs quintessential function indecision-making processes, where overall performance is measured with the aid of trendy indications and relevant at one-of-a-kind practical ranges e.g., ministry, institution, universities, faculty, branch etc. The standard indications determine expenditure, extent and quality of lookup posted and designs patented. It is an vital hazardous element for profitable execution of a variety of countrywide improvement programs. It is integral for the national governments to be familiar with quantified values of research input and output, and be aware with the priorities of countrywide plans to acquire successful execution of strategies (Al-Turki, Bilgrami et al. 2015).

One of the modern day inclinations of training and machine of higher education in particular is a dynamic transition to administration system based on key performance indicators (KPIs). KPI provide probability to evaluate the performance of movements of man or woman personnel and additionally of unique divisions (departments, lookup laboratories, scientific centers, faculties, branches) and of instructional group as a whole. However in order to practice KPI it is essential to take into account many factors and additionally to consider 
50-year ride of overseas schooling device of making use of one of a kind overall performance indications for evaluation of effects of scientific and academic institutes as a complete and outcomes of individual researchers and instructors (Luneva 2015).

The main dreams of this paper are: (1) reviewed some scientific research with KPIs in distinctive research universities, as well as (2) modified many current KPIs and proposed others primarily based on the IMAMU's requirements, standards and ideology. With its own KPIs the IMAMU will deliver accountability, transparency and responsibility among its faculties, personnel and college students paving way to academic and scientific lookup improvement in order to be the position mannequin for different lookup universities in Saudi Arabia.

\subsection{Key Performance Indicators}

Goedegebuure, et al (1990) note that "an authoritative definition of performance indicators does not exist", and while they are frequently thinking to be fully quantitative, "qualitative performance warning signs exist too"(Findlay 1990). For example, Cuenin (1987) acknowledged that at the very least a overall performance indicator is a numerical value: which provide(s) a size for assessing the quantitative overall performance of a system. When the indicator indicates a difference in one direction, this ability that the situation is higher whereas if it shows a distinction in the contrary path then this capability that the state of affairs is much less favorable (Cuenin 1987).

Cuenin (1987) is one of many commentators who has diagnosed the need for higher clarity in definition of performance indicators, a undertaking taken up by means of quite a number peak bodies such as the Organization for Economic Co-operation and Development's (OECD) Institutional Management in Higher Education's Performance Indicators Work group initiated in 1989 (Cuenin 1987).

The Workgroup defines performance indications as "signals derived from databases or from opinion records that indicate the want to explore deviation from both normative or different preselected tiers of activity or performance"; symptoms "monitor tendencies or performance, signal the want for in addition examination of issues or conditions, or assist in assessing quality" (Kells 1992). Kells (1992) additionally pointed out that there are at least three one-of-a-kind sorts or categories of indicators: "1) Indicator to screen institutional response to authority's goals or policies; 2) Indicators of teaching/learning, lookup and service; and 3) Indicators needed in college (Kells 1992).

The heightened hobby in overall performance symptoms is due to many factors, now not the least of which are an institutional want to implement more superb strategic planning mechanisms and authorities demands for higher efficiency and effectiveness on the one hand, and enhancement of the quality of greater schooling on the other. The elevated use of performance symptoms desires to be viewed as part and parcel of a broader go to entrench an 'evaluative culture' in higher training institutions and systems, fuelled through the twin demands of accountability and excellent assurance (Meek and van der Lee 2005).

KPIs provide pleasant assurance to the scientific lookup and higher education. The KPIs are variable and designed especially for a specific entity such as education, research, finance, operation, management etc. Nevertheless, each one has its personal criteria and desires to acquire the nice performance in order to carry worldwide competitiveness. The KPIs are designed to improve and screen progress as properly as success in a specific sector, which have hardly ever been proposed singularly and surprisingly for an academic and scientific research institute such as the university.

Performance indicators used at the countrywide stage are designed to: (1) Ensure accountability for public cash (2) Verify the quality of new institutions (3) Assign institutional fame (4) Stimulate opposition within and between institutions (5) Improve the high-quality of higher schooling provision (6) Facilitate global comparisons (7) Underwrite transfer of authority between the kingdom and institutions (Fisher, Rubenson et al. 2008).

The following are some general principles that should be followed while developing KPIs:

1. Accountability and Performance Measurement: The targeted performance description, which is described in measurable terms through the KPIs, must be deployed to the organizational level that has the authority and knowledge to take the necessary action and ensure accountability.

2. Reliability and Validity: KPI information should be free from bias and methodology error, complete, and described in a factual and logical manner. KPI information should also be able to stand a validation exercise by impartial external agencies.

3. Improvement: KPIs should not be an end in themselves, but be considered as an aid to management. They are a starting point of a properly informed debate that should lead to a plan for improvement.

4. Benchmarking: KPIs should be benchmark-able. However, they should be seen primarily within their 
local context and should have more a meaning as a comparison over time than as a comparison between organizations in the peer group.

5. Relevance: KPI information should be relevant to the decision-making needs of user groups. It should be aligned to the strategic objectives but sometimes can be tactical; i.e., operationalizing strategic objective but more in response to the environment.

6. Clarity and Consistency: KPI information should be clear to a wide range of relevant stakeholders. KPI information should, where relevant, be consistent with data from other initiatives, organizations, or jurisdictions.

\subsection{Types of Performance Indicators}

There is general agreement on the four types of performance indicators as Input, Output, Outcome, and Process. These can be more broadly categorized as Quantitative and Qualitative indicators. The descriptions of these types are as follows:

\subsubsection{Quantitative Indicators}

\subsubsection{Input Indicators}

Input indicators reflect the human, financial and physical resources involved in supporting institutional programs, activities and services. Limitations concerning input indicators surround their inability to determine the quality of teaching and learning without extensive interpretation. For example, an indicator such as resource allocation should be interpreted with enrolment data (to determine resource to student ratio), resource quality (i.e. condition) and conceptual range (e.g. library book topics) to determine teaching and learning quality (Chalmers 2008).

\subsubsection{Output Indicators}

Output indicators are subject to similar limitations. Output data reflects the quantity of outcomes produced, including immediate measurable results, and direct consequences of activities implemented to produce such results (Chalmers 2008). The defining feature is quantity or numerical amount, and the quality of these numbers is almost entirely disregarded. Input and output measures are inherently constrained by their data-driven "quantitative" nature, which prohibits the investigation of instructional, interactive and learning processes crucial to the quality of an institution, its educational programs and its graduates. As such, quantitative performance indicators do not demonstrate quality of education, but rather quantities of its outcomes (Burke, Minassians et al. 2002). There is limited empirical support for quantitative indicators as enhancers of teaching and learning quality. However, qualitative measures have received significant support as they focus on quality aspects and allow measurement of deep and complex issues, of which the Higher Education system is invariably composed. The use of qualitative as opposed to 5 quantitative indicators provides information that allows a deeper understanding of the variable measured.

\subsubsection{Qualitative Indicators}

\subsubsection{Outcome Indicators}

Outcome measures focus on the quality of educational program, activity and service benefits for all stakeholders. These key stakeholders include students, parents, the community, employers and industry (Warglien and Savoia 2001). Outcome performance indicators typically do not involve generating the quantity of outcomes in the form of numerical data (as do output performance indicators), but instead measure complex processes and results in terms of their quality and impact. This is the difference between output and outcome measures. While they both measure the effects of higher education, output performance indicators measure this quantitatively, and outcome measures do this qualitatively.

\subsubsection{Process Indicators}

Process indicators are those which include the means used to deliver educational programs, activities and services within the institutional environment. These measurements look at how the system operates within its particular context, accounting for institutional diversity, a common confounding factor in inter- and intra-institutional comparison.

\section{Literature Review}

This section opinions the scientific research with KPIs in unique countries like New Zealand, Australia, Ireland, UK, Germany, Malaysia, United State of America (USA), Russia, and Saudi Arabia. As well as reviewing some case studies of KPIs for a scientific research designed at some research universities in any other country.

Research universities in New Zealand have adopted three types of lookup indicators with KPIs, constrained to 
the variety of research postgraduates, tools services and expenditure. The other five indications measure research output, scientific degrees awarded, publications, lookup income and percent value recovery. In order to measure research outcome, the wide variety of citations, range of college engaged, worldwide collaboration, monetary have an impact on and technological know-how switch were precise as the indicators.

Research universities in Australia like Sydney college has developed seventeen kind of warning signs and solely two types of scientific lookup with KPIs, restricted to the research income and research output. The rest of other fifteen indications measure the areas of student diversity, student outcomes, financial sustainability, manufacturer and group of workers satisfaction.

A case find out about from health data and nice authority in Ireland's fitness and social care offerings has adopted two kinds KPIs, limited to popular KPIs measure components of overall performance relevant to the majority of carrier and specific KPIs are associated to a particular service person populace and measure particular elements of care related to those provider customers (Wakai, Sullivan et al. 2013).

The Research Universities in UK has applied eight kinds of lookup indications with KPIs, three are limited to the number of lookup postgraduates, expenditure and equipment facilities. The different five warning signs measure research output, publications, scientific degrees awarded, percentage price recovery and lookup income. In order to measure research outcome, the variety of citations, international collaboration, wide variety of school engaged, economic have an impact on and technological know-how switch had been distinct as the warning signs (Kyrillidou 1996). Also, UK's Research Assessment Exercise (RAE) looks at performance based on the fantastic and extent of research. Institutions make submissions to the RAE each and every 5-7 years, with the submission made up of self-selected records from units of assessment within the organization (roughly equal to a department). Within each unit of assessment, person researchers may additionally only put up a fixed quantity of outputs for assessment.

Research universities in Germany has adopted 4 kinds of scientific research with KPIs that restricted to third birthday party funding, relative to range of professors, amount of third party funding by using source and variety of doctorates and post-doctorates (Box 2010).

Finland's universities receive their simple funding as core funding, with $75 \%$ calculated on the groundwork of the excellent and extent of things to do in training and lookup and researcher education, and $25 \%$ primarily based on other education and science policy considerations. The large allocations are set out below. Essentially, round $34 \%$ of whole core funding is primarily based on a performance-based assessment of the extent of activities and the quality and effectiveness of research and researcher education (Box 2010).

Research universities in Malaysia have special eight scientific research with KPIs i.e., extent and pleasant of research (30\%), performance, importance and capacity of researchers (25\%), performance of postgraduates (5\%), variety of postgraduates (10\%), service best (7\%), innovation (10\%), equipment \& facilities (5\%) and networking (8\%) (Kahn, Blankley et al. 2008). Most of the lookup indicators centered research can provide for science and technology, publications, post-doctoral appointments and research expenditure. The innovation symptoms were the patents, technological know-how know-how, commercialized products, copyrights and licensing (Kahn, Blankley et al. 2008).

Research college in USA has adopted 5 sorts of scientific research with KPIs (Ugwu and Haupt 2005), The description of these KPIs as:(1)Quantitative Indicators - introduced as a wide variety answering a scientific question. (2) Practical Indicators - relevant to present experimental design or process in the laboratory. (3) Directional Indicators - interrelated to the vision, theories and hypotheses, presently entertained and tested in the laboratory. (4) Actionable Indicators - are related to the control and impact over change. Such alternate for example are the variables in your experimental design. (5) Financial Indicators - applicable to cost and day-to-day operation of research (Ugwu and Haupt 2005).

In spring of 2013, fifty four Russian universities applied to the contest to acquire government aid for aggressive boom amongst the main world scientific and educational core according to the Regulation of the Government of the Russian Federation dated 16 March, 2013 No. 211 "About measures of authorities aid of the leading Universities of the Russian Federation aimed at their aggressive growth among the main world scientific and educational centers" (Luneva 2015).

Ministry of Higher Education, Saudi Arabia accepted certain quantitative and qualitative lookup warning signs with KPIs for evaluating research in greater schooling institutions (Schneider 2010). A case study in for King Abdul-Aziz University, Jeddah, Saudi Arabia have designed lookup warning signs with KPIs for three essential parameters as: first, the capacity of the institution and scientific based facilities; second, the pursuits and targets of institutions strategic plan; and the third, the global indicators as approved by companies for the classification 
of world universities are used to measure the growth of university research, objectives, targets and the strategic plan (Al-Turki, Bilgrami et al. 2015).

As the majority of conclusion ensuing from the literature overview of scientific research with KPIs is various in its meant purpose. Accordingly, the use of scientific lookup with KPIs is most dependable and valid when used as a group.

\section{Method and Material}

The study was conducted in IMAMU, Saudi Arabia using a qualitative method in semi-structured interview and observation towards the respondents. The main objective is to study the implementation of scientific research with KPIs in this Saudi government university. This IMAMU has been chosen among all as they become the research university in the implementation scientific research with KPIs since Deanship of Scientific Research in IMMAU announced to follow the recommendations approved by Ministry of Higher Education, Saudi Arabia the effort to further enhance their research performance to achieve their vision, mission and objectives.

\section{Results and Discussions}

\subsection{Deanship of Scientific Research at IMAMU: Goals and Responsibilities}

Deanship of Scientific Research at IMAMU is doing a great outstanding job in bringing current scientific knowledge through international scientific collaborations, publications in ISI journals and procuring maximum funding for the development of science and technology. In the light of such developments, Deanship of Scientific Research has to evolve further to embrace highest degree of accountability transparency, and responsibility from participating researchers. Such goals are achievable, if human resources implement techno-scientific programs such as skilled and non-skilled trainings and orientations under established terms and conditions as set forth by various disciplines and regulate compliance by individuals.

The following are some advantages of transformation of human resources (Al-Turki, Bilgrami et al. 2015):

1. Generate techno-scientific database depending on the knowledge, experience, training, exposure etc., of trained personals.

2. Global connection that connects employees with hiring companies both within and outside of the country.

3. Identify challenging issues related to the university, departments and individuals.

4. Assist individual researchers to compete with international standards.

5. Creating strong database for highly skilled individuals to become national pool for technology employers, thus reducing gaps between input and output of the university.

6. Help workforce individuals to stay abreast with the latest knowledge in science and technology.

7. Validate qualification and experience of the employees, and training by accredited agencies.

Last, but not the least, transformation of human resources will bring professional development, self-directed and employer sponsored studies besides accredited and non-accredited courses. In the light of defined practices, set of established KPIs, science and technology manager will make effective, transparent and productive judgments. Subsequent modifications in the scientific and technical programs, changes in research policies and the introduction of best scientific practices are easily applied on the basis of above criteria.

\subsection{Overall Priorities of Scientific Research in IMAMU}

Deanship of Scientific Research in IMAMU established set of scientific research priorities, and corresponding practical research challenges, designed to increase investment in areas of immediate and critical importance to Saudi Arabia. The current scientific research priorities are: Islamic and Arabic language sciences, forensic sciences, humanities and social sciences, economics and administrative sciences, media and communication sciences, history of Islamic-Arab sciences, health sciences, and applied sciences.

\subsection{Scientific Research with KPIs in IMAMU}

Scientific research in Saudi Arabia needs special attention from governing bodies and those who are already involved in scientific research. Progress in scientific research in IMAMU is slow but directly proportional to the rates of development and financing of higher education and to the rates at which research institutes and universities are established and expanded. The relationships as described above are significant signs of improving scientific research in Saudi Arabia.

Earlier attempts to implement performance indicators in IMAMU partially succeeded. The reason was disparity 
between implementation of KPIs and institutional strategic planning, goal, mission and vision. Such disparities are removed and modifications presented in this paper to implement KPIs in IMAMU.

\section{Conclusion}

During recent times, scientific research in the universities is under pressure. The expectations are significantly high to bring quality, excellence, innovation and financial outcome. The expectations from scientific research in the universities enforced performance indicators as the criteria to measure university progress towards national goals and specific contributions made for the benefit of university and nation.

Overall, the use of KPIs to measure the organization performance is much needed not only for the Saudi public universities but Saudi private universities as well. This study attempt to look at the implementation of KPIs in the Saudi public university mainly IMAMU and found that this initiative adopted from the private sectors shows a positive research impact on the performance of university. By taking IMAMU, Saudi Arabia as the main focus, the study shows that this university in using KPIs is success in measuring their research performance not only for the university as a whole but their staff performance as well. The findings of this study shows that the scientific research based on KPIs delivered and developed according to the priority of scientific research in all university's faculties by the Deanship of Scientific Research are achieved their targets to be in line with their mission and vision.

There are several recommendations that will be made for future research and modifications on this matter. Since IMAMU usually develop their KPIs to measure the three main aspects such as work-process, customers' satisfaction financial aspects, it is recommended that IMAMU should measure their performance by looking also at their corporate social responsibility perspectives.

In future research, the Ministry of Higher Education, Saudi Arabia should provide the best indicators to measure the performance of Saudi universities by putting some value added in implementation of KPIs. Furthermore, third parties such as government servant and stakeholders should togetherness in performing their jobs to make sure everybody is complying with KPIs sets by its agencies.

\section{Acknowledgments}

The authors acknowledge the financial and technical support provided by the Deanship of Scientific Research, IMAMU, Riyadh, Saudi Arabia.

\section{References}

Al-Turki, Y. A., \& Bilgrami, A. L. et al. (2015). A Case Study of Key Performance Indicators in Scientific Research in a Middle Eastern University. International Journal of Latest Research in Science and Technology, 4(5), 21-28.

Annett, M. K. (2009). The SNaP Framework: A User-Friendly VR System for Research on Spatial Navigation. University of Alberta.

Box, S. (2010). Performance-based funding for public research in tertiary education institutions: Country experiences (pp. 85-126).

Burke, J. C., \& Minassians, H. et al. (2002). State Performance Reporting Indicators: What Do They Indicate? Planning for Higher Education, 31(1), 15-29.

Chalmers, D. (2008). Teaching and learning quality indicators in Australian universities. Outcomes of higher education: Quality relevance and impact, 8-10.

Cuenin, S. (1987). The Use of Performance Indicators in Universities: An International Survey. International Journal of Institutional Management in Higher Education, 11(2), 117-139.

Findlay, P. (1990). Developments in the performance indicator debate in the United Kingdom. Peer Review and Performance Indicators, 125-134.

Fisher, D., \& Rubenson, K. et al. (2008). Performance indicators: A summary. A study funded by the Humanities and Social Science Federation of $\mathrm{Canada/FÃ} \odot \mathrm{d} \tilde{A} \odot$ ration canadienne des science humaines et sociales Retrieved 2.

Kahn, M., \& Blankley, W. et al. (2008). Measuring R\&D in South Africa and in Selected SADC Countries: Issues in Implementing Frascati Manual-Based Surveys, Working Paper prepared for the UIS. Montreal: UIS.

Kells, H. R. (1992). An Analysis of the Nature and Recent Development of Performance Indicators in Higher 
Education. Higher Education Management, 4(2), 131-138.

Kyrillidou, M. (1996). Current context for performance indicators in higher education, August.

Luneva, E. V. (2015). Key Performance Indicators (KPI) System in Education. Asian Social Science, 11(8), 194. https://doi.org/10.5539/ass.v11n8p194

Meek, V. L., \& J. J. van der Lee (2005). Performance indicators for assessing and benchmarking research capacities in univerisites.

Schneider, J. W. (2010). Bibliometric Research Performance Indicators for the Nordic Countries: A publication from the NORIA-net. The use of bibliometrics in research policy and evaluation activities.

Ugwu, O. O., \& Haupt, T. C. (2005). Key performance indicators for infrastructure sustainability-a comparative study between Hong Kong and South Africa. Journal of Engineering, Design and Technology, 3(1), 30-43. https://doi.org/10.1108/17260530510815321

Wakai, A. R., \& Oâ€ ${ }^{\mathrm{TM}}$ Sullivan, et al. (2013). Development of key performance indicators for emergency departments in Ireland using an electronic modified-Delphi consensus approach. European Journal of Emergency Medicine, 20(2), 109-114. https://doi.org/10.1097/MEJ.0b013e328351e5d8

Warglien, M., \& Savoia, M. (2001). Institutional experiences of quality assessment in higher education-The University of Venice (Italy). Organization for Economic Co-operation and Development (OECD). Retrieved from http://www.oecd.org/dataoecd/48/49/1871205.pdf

\section{Copyrights}

Copyright for this article is retained by the author(s), with first publication rights granted to the journal.

This is an open-access article distributed under the terms and conditions of the Creative Commons Attribution license (http://creativecommons.org/licenses/by/4.0/). 